\title{
Distribution and Stability of Quinone Outside Inhibitor Fungicide Resistance in Populations of Potato Pathogenic Alternaria spp. in Wisconsin
}

\author{
Shunping Ding, ${ }^{1,2}$ Dennis A. Halterman, ${ }^{1,3}$ Kiana Meinholz, ${ }^{1}$ and Amanda J. Gevens ${ }^{1, \dagger}$ \\ ${ }^{1}$ Department of Plant Pathology, University of Wisconsin-Madison, Madison, WI 53706 \\ ${ }^{2}$ Wine and Viticulture Department, California Polytechnic State University, San Luis Obispo, CA 93407 \\ ${ }^{3}$ Vegetable Crops Research Unit, U.S. Department of Agriculture Agricultural Research Service, Madison, WI 53706
}

\begin{abstract}
Quinone outside inhibitor (QoI) fungicides have been an important class in managing potato early blight caused by Alternaria solani and brown spot caused by A. alternata. Because of the single-site mode of action character of QoI fungicides, which are relied on for management of diseases in Wisconsin, and the abundant asexual conidia production of the Alternaria species, pathogen isolates with QoI resistance have been detected after just a few years of QoI fungicide usage in commercial production fields. Resistance to QoIs has been attributed to amino acid substitutions F129L and G143A in cytochrome $b$ of A. solani and A. alternata, respectively, as a result of point mutations. The aim of this study was to assess Alternaria populations in Wisconsin for QoI resistance before and after fungicide applications in order to evaluate resistance stability. A TaqMan single nucleotide polymorphism genotyping assay was designed based on the sequences of the cytochrome $b$ gene from Alternaria isolates collected in Wisconsin to profile QoI resistance in Alternaria populations as well as to explore factors that may influence frequency of QoI resis-

the frequency of $A$. solani isolates with the F129L mutation was consistently high and showed primarily the TTA mutation type. The frequency of A. alternata isolates with the G143A mutation started relatively low and increased at the end of the production season in each year $(P=0.0109, P=0.2083$, and $P=0.0159)$. A potato field managed without use of QoI fungicides showed a significantly lower $(P<0.05)$ frequency of A. alternata isolates carrying G143A than conventionally managed potato fields. The overall frequency of A. alternata isolates carrying G143A in the four locations was similar over the 3 years $(P=0.2971)$. The QoI resistance characteristics of the isolates were stable even when QoI selection pressure was removed for at least five subculture transfers, and the mutation types of codons 129 and 143 in the cytochrome $b$ gene in A. solani and A. alternata, respectively, remained the same. This indicated that the application of QoIs in the field is not the sole factor responsible for the variation of the frequency of QoI resistance in the pathogen populations.
\end{abstract} tance in the pathogen populations. This assay successfully identified the mutations conferring QoI resistance in isolates collected from four locations each year from 2015 to 2017. During the course of this study,
Keywords: fungicide resistance, potato early blight, potato brown spot, Alternaria spp.
Potato early blight, caused by Alternaria solani, and brown spot, caused by A. alternata, are two persistent potato foliar diseases that require routine fungicide applications for mitigation of yield and quality loss. Generally, brown spot is a relatively minor disease of potato compared with early blight. Foliar necrotic lesions and chlorosis caused by Alternaria spp. are common in Wisconsin and are usually first observed in early July and persist to harvest, if unmanaged. Reduced photosynthesis from necrosis can result in yield loss up to $30 \%$ annually in the case of early blight (Shtienberg et al. 1990). The pathogens have similar life cycles, as both are asexually propagated and cause polycyclic diseases with initial conidial inoculum dispersed by wind and rain splash (Agrios 2005; McCartney et al. 1993; van der Waals et al. 2003). Currently all predominant commercial potato varieties are susceptible to early blight and brown spot, and control is achieved with fungicides. In Wisconsin, a potato physiological day accumulation of 300 is used to guide the initial preventive fungicide application based on its validated association with an increase in conidia production (Pscheidt and Stevenson 1986). Because of the polycyclic nature of the diseases, subsequent fungicide applications are typically applied on a 7-day spray schedule

${ }^{\dagger}$ Corresponding author: A. J. Gevens; gevens@wisc.edu

Funded: This project was partially funded by the University of WisconsinMadison Hatch Formula grant program.

*The $\boldsymbol{e}$-Xtra logo stands for "electronic extra" and indicates that three supplementary figures are published online.

Accepted for publication 17 March 2019.

@ 2019 The American Phytopathological Society until vines are chemically desiccated at around 2 weeks prior to harvest.

Single-site mode of action fungicides have been used in managing early blight and brown spot since their registration in 1999, and fungicide resistance has been a progressive problem in many commercial fields (Pasche and Gudmestad 2008; Pasche et al. 2004; Rosenzweig et al. 2008a). One such single-site mode of action fungicide class is quinone outside inhibitors (QoIs), which have broad protection against both fungi and oomycetes and reduced negative effects on human health and the environment (Rosenzweig et al. 2008b; Tymon and Johnson 2014). By binding cytochrome $b$, QoI fungicides interrupt mitochondrial respiration to interfere with energy generation (Bartlett et al. 2002). Because they are highly effective in managing disease when the pathogen population is sensitive, QoI fungicides have been favored and used in many potato production regions (Pasche et al. 2004; Rosenzweig et al. 2008a). QoIs were initially released for early blight control, and they provided outstanding management of disease. However, because of its single-site mode of action, insensitive isolates within populations have been selected and prevailing insensitivity or resistance has accumulated quickly. Many studies have shown that single nucleotide mutations within the cytochrome $b$ gene in targeted pathogens result in partial or complete resistance to QoIs (Ma and Michailides 2004; Pasche et al. 2004; Rosenzweig et al. 2008b). Several amino acid changes as a result of single nucleotide mutations may confer resistance, such as F129L, G137R, and G143A (Grasso et al. 2006). The F129L mutation, in particular, is known to confer partial resistance to QoI fungicides in A. solani (Bauske et al. 2018; Rosenzweig et al. 2008b). A G143A mutation in A. alternata confers complete resistance to QoI fungicides (Ma and Michailides 2004; Vega et al. 2012).

QoI resistance in Alternaria spp. has been reported in many regions. In the early 2000s, the majority of isolates from Wisconsin field populations demonstrated QoI resistance (Rosenzweig et al. 2008a), and the frequency was higher than $90 \%$ in Wisconsin after 
2013 (Bauske et al. 2018). QoI resistance in A. solani has also been reported in Idaho, North Dakota, and Washington in the United States (Fairchild et al. 2013; Pasche et al. 2005; Tymon and Johnson 2014) as well as in other countries (Leiminger et al. 2014). QoI resistance in A. alternata has been reported in Idaho and Washington on potatoes (Fairchild et al. 2013; Tymon and Johnson 2014), and in Florida and California on other plant hosts (Karaoglanidis et al. 2011; Vega and Dewdney 2014). In Wisconsin and other potato producing regions, the reliance on QoI fungicides for the management of potato early blight and brown spot has decreased over the past 20 years owing to the reduced effectiveness of QoIs as a result of pathogen resistance in the field. Currently, QoI fungicides are still utilized in potatoes, but the targeted diseases are primarily below ground and include silver scurf, black dot, and Rhizoctonia root rot. Despite the general trend toward reduced foliar use of QoI fungicides, some growers still apply QoIs such as azoxystrobin (AZ) and pyraclostrobin, although not more than twice per growing season and usually mixed with a second fungicide of a different mode of action and in the early season for controlling early blight and brown spot together. QoI resistance in A. alternata has not been previously studied in Wisconsin and QoI resistance in A. solani has not been systematically studied in the state since 2002 (Rosenzweig et al. 2008b). With the change of fungicide programs, a contemporary assessment of QoI resistance in the field is needed to improve disease management recommendations.

The QoI resistance conferred by F129L in A. solani and G143A in $A$. alternata was not correlated with a fitness cost according to previous studies, indicating that the mitochondrial genotypes of the pathogens may be stable (Pasche and Gudmestad 2008; Vega and Dewdney 2014). The stability of phenotypic resistance and the efficacy of QoIs from year to year are not known. This information is very important to growers when they are making fungicide selection decisions. Therefore, the objectives of this research were to (i) assess A. solani and A. alternata populations in Wisconsin for QoI resistance by detecting the correlated mutations in cytochrome $b$, (ii) compare the frequency of resistant isolates before and after QoI application each season, and (iii) investigate the stability of QoI resistance by subjecting isolates to QoI selection pressure.

\section{Materials and Methods}

Sample collection. Sample collections were conducted in four potato fields in Plover, Hancock, Grand Marsh, and Madison, Wisconsin, each year from 2015 to 2017 (Table 1). The field located in Madison was organically managed and did not receive QoI fungicides, and the rest were commercial conventional fields. Each field was divided into five sections and from each section, five potato plants (at least $10 \mathrm{~m}$ away from each other) showing early blight and brown spot symptoms were arbitrarily selected for sampling. One symptomatic compound leaf was taken from each selected plant as one sample and all together 25 symptomatic compound leaf samples were taken from each field. Every field was visited twice, once before the foliar application of QoI fungicides (late June) and once in late August.

Isolation and identification. For each sample, lesion margins were excised from each compound leaf, surface sterilized with
$70 \%$ ethanol for $30 \mathrm{~s}$, and incubated on antibiotic-amended water agar (with $0.25 \%$ ampicillin and $0.05 \%$ rifampicin) to isolate the pathogens. Multiple lesions from each leaf were excised and cultured on individual Petri dishes, but only one single conidium from all resulting colonies with the same conidial morphology was picked and subcultured onto clarified antibiotic-amended V8 (CV8) juice agar (with $0.125 \%$ ampicillin and $0.05 \%$ rifampicin). To encourage sporulation, all cultures were incubated under $20 \mathrm{~h}$ of light and $4 \mathrm{~h}$ of darkness at $21^{\circ} \mathrm{C}$ for 2 weeks. Based on conidia morphology, isolates producing long conidia (70 to $90 \mu \mathrm{m}$ ) with long beaks (30 to $40 \mu \mathrm{m})$ were putatively classified as $A$. solani. Isolates producing small conidia ( 25 to $35 \mu \mathrm{m}$ ) with short beaks (4 to $6 \mu \mathrm{m}$ ) were putatively classified as A. alternata.

For each Alternaria isolate, total DNA was extracted following the protocol of Bok and Keller (2012). The Alt a 1 gene was amplified using the primer pair Alt-for and Alt-rev (Hong et al. 2005). Amplification products were purified with the GenElute PCR Clean-Up Kit (Sigma-Aldrich) and sequenced at ProteinCT Biotech (Madison, WI). The sequences were aligned with reference sequences of $A$. solani and A. alternata, respectively, to corroborate the species identification.

Sequencing of cytochrome $b$ (partial) and the TaqMan single nucleotide polymorphism genotyping assay. Amplification of cytochrome $b$ from $A$. alternata was performed with primers DTRcytb2 (Grasso et al. 2006) and AacytbR (5'-TGTAACCGTCTCCGTCTATCAATC- $\left.3^{\prime}\right)$ at the annealing temperature of $52^{\circ} \mathrm{C}$ for $A$. alternata. AacytbR was designed based on the sequence of the GenBank accessions JQ446323 and JQ437357 (Vega et al. 2012). Amplification of cytochrome $b$ from $A$. solani was performed with primers As5F and Asint129_r (Grasso et al. 2006) at the annealing temperature of $60^{\circ} \mathrm{C}$ with High-Fidelity PCR polymerase following the manufacturer's recommended protocol (Clontech Laboratories Inc.). The above amplified segments were directly sequenced, and sequences were deposited in GenBank (accession numbers MH268171 and MH268172). Partial cytochrome $b$ sequences of both species with mutations denoted were submitted to the Custom TaqMan Assay Design Tool (Thermo Fisher Scientific) for primer and probe designs to conduct the TaqMan single nucleotide polymorphism (SNP) genotyping assay (Table 2). The quantitative PCR (qPCR) was performed with total DNA of the isolates diluted to $10 \mathrm{ng} / \mu \mathrm{l}$. Each qPCR reaction included $12.5 \mu$ of $2 \times$ TaqMan Master Mix, $1.25 \mu \mathrm{l}$ of $20 \times$ Assay Working Stock, $2 \mu$ l of diluted DNA, and $9.25 \mu \mathrm{l}$ of Nuclease-Free Water (Thermo Fisher Scientific). The cycling conditions of qPCR included a single incubation at $95^{\circ} \mathrm{C}$ for $10 \mathrm{~min}$, followed by 40 cycles of denaturation at $95^{\circ} \mathrm{C}$ for $15 \mathrm{~s}$ and annealing/extension at $60^{\circ} \mathrm{C}$ for $1 \mathrm{~min}$. The qPCR reactions were conducted using a CFX96 Real-Time PCR Detection System (BioRad Laboratories Inc.) and data were analyzed with Bio-Rad CFX Maestro software (version 4.0; Bio-Rad Laboratories Inc.).

QoI resistance stability test. Three isolates of $A$. solani and three isolates of A. alternata were chosen for a QoI resistance stability test based on the cytochrome $b$ mutation types identified by the TaqMan SNP genotyping assay (Table 3). AZ, a common and representative QoI fungicide, was used to amend the media for this test. All of these isolates were grown on CV8 agar amended with $\mathrm{AZ}$ and CV8 agar without $\mathrm{AZ}$ continually for five subculture transfers with single

Table 1. Origin, number of applications of quinone outside inhibitor (QoI) fungicides, and collection year for Alternaria solani and A. alternata isolates characterized for the presence or absence of mutations associated with QoI resistance ${ }^{\mathrm{Z}}$

\begin{tabular}{|c|c|c|c|c|c|c|c|c|c|}
\hline \multirow[b]{3}{*}{ Location } & \multicolumn{3}{|c|}{2015} & \multicolumn{3}{|c|}{2016} & \multicolumn{3}{|c|}{2017} \\
\hline & \multirow[b]{2}{*}{ QoI } & \multicolumn{2}{|c|}{ Isolates } & \multirow[b]{2}{*}{ QoI } & \multicolumn{2}{|c|}{ Isolates } & \multirow[b]{2}{*}{ QoI } & \multicolumn{2}{|c|}{ Isolates } \\
\hline & & A. solani & A. alternata & & A. solani & A. alternata & & A. solani & A. alternata \\
\hline$\overline{\text { Arena }}$ & 2 & 16 & 21 & 1 & 43 & 31 & 1 & 25 & 47 \\
\hline Hancock & 0 & 17 & 28 & 1 & 17 & 21 & 3 & 18 & 41 \\
\hline Plover & 2 & 15 & 12 & 0 & 28 & 40 & 2 & 24 & 36 \\
\hline Madison & 0 & 4 & 27 & 0 & 21 & 39 & 0 & 3 & 48 \\
\hline Total & & 52 & 88 & & 109 & 131 & & 70 & 172 \\
\hline
\end{tabular}

${ }^{\mathrm{z}}$ One field from each location was studied every year from 2015 to 2017 . QoI indicates number of times that a QoI fungicide was applied in each sampling year. 
conidia. Each subculture transfer was grown for 7 or 10 days under the same conditions for sporulation. Mycelia were measured on day 10 postplate inoculation by measuring the radius of the growth for $A$. solani and on day 7 for $A$. alternata. Growth radii were averaged from two perpendicular measurements. After the measurement, the plates were flooded with water amended with Tween 20 , and conidia suspensions were collected and adjusted to 5,000 conidia/ml. Then $10 \mu$ l of the conidia suspension was transferred to plates of water agar containing $0,0.001,0.01,0.1,1$, and $10 \mathrm{mg} / \mathrm{liter}$ of $\mathrm{AZ}$ and $100 \mathrm{mg} /$ liter salicylhydroxamic acid (SHAM). SHAM was used to inhibit alternative oxidase pathways that are potentially utilized by AZ-resistant Alternaria isolates (Fan et al. 2015; Rosenzweig et al. 2008a; Tymon and Johnson 2014; Ziogas et al. 1997), and we confirmed that $100 \mathrm{mg} / \mathrm{liter}$ of SHAM had no deleterious effects on conidia germination of the selected isolates following Pasche et al. (2004). After incubation for $4 \mathrm{~h}$ under ambient conditions on a laboratory bench top, the germinated and nongerminated conidia were counted. The $\mathrm{EC}_{50}$ value of each subculture was calculated with the germination rate following the method described by Rosenzweig et al. (2008a). Using the same culture plates, the conidia and mycelia were collected for DNA extraction and subsequent TaqMan assays to detect the stability of the genotype of the cytochrome $b$ genes over the serial transfers.

Statistical analysis. The overall frequency of Alternaria isolates carrying the mutations conferring QoI resistance was compared across the four locations using the Tukey test in SAS (SAS Institute). The frequency of QoI resistance from each year was compared using the Pearson $\chi^{2}$ test in $\mathrm{R}$ software (version 3.4.2; R Core Team) for each location and overall to test whether the frequency changed from 2015 to 2017.

The ratio of QoI resistance from each location from early season to late season was compared with a $t$ test, and the cutoff to determine significant differences was set at $\alpha=0.05$.

Mycelial growth of each isolate was compared among subcultures 1,3 , and 5 grown on $1 \mathrm{mg} /$ liter of AZ plus SHAM and on CV8 using Proc GLM analysis in SAS, and significant differences were determined at the $\alpha=0.05$ level using the Tukey test. $\mathrm{EC}_{50}$ values of the isolates were compared using the same analysis method as the growth rate.

\section{Results}

Isolation and identification. Based on morphological characteristics and Alt a 1 sequencing results, 52, 109, and 70 isolates of $A$. solani were retrieved from 2015, 2016, and 2017, respectively. A total of 88,131 , and 172 isolates of A. alternata were retrieved from 2015 , 2016, and 2017, respectively (Table 1). The cytochrome $b$ sequence of $A$. solani was genotype II according to Leiminger et al. (2014). The cytochrome $b$ sequence of $A$. alternata was the same as the A. alternata cytb profile I documented by Vega et al. (2012).

Development of primers and probes. Our results indicated that the TaqMan SNP genotyping assay was successful in discriminating different genotypes of codon 129 in A. solani and codon 143 in $A$. alternata. Therefore, the TaqMan SNP genotyping assays designed in this study were adequate to identify the mutation types at amino acid position 129 in cytochrome $b$ of $A$. solani by pairing the probes identifying TTG and TTA and the probes identifying CTC and TTC. The probes designed for A. alternata also successfully detected the presence of mutations at amino acid position 143 in cytochrome $b$. All of the A. solani isolates carried the wild-type allele TTC at codon 129 (Supplementary Fig. S1). Most isolates also carried the mutated allele TTA, indicating mixed mitochondrial genomes (Supplementary Fig. S2). In addition, a few A. solani isolates showed mixed mutation genotypes at codon 129 . However, most of the isolates for $A$. alternata carried either the wild-type allele GGT at codon 143 or the mutated allele GCT (Supplementary Fig. S3).

Determination of spatiotemporal distribution frequency of mutations conferring QoI resistance in $A$. solani. All of the $A$. solani isolates collected from 2015 to 2017 carried the mutations at amino acid position 129 in the cytochrome $b$ gene. Among the mutant types, TTA was most common, followed by TTG and CTC, in 2015 and 2017. TTA was also the most common type, followed by CTC and TTG, in 2016. Most of the isolates showed only one type of mutation in cytochrome $b$, but two types of mutations were observed in several isolates (Table 4).

Table 2. Primers and fluorescent-labeled probes used in the quantitative PCR assay in detecting single nucleotide polymorphisms in the cytochrome $b$ gene in Alternaria solani and A. alternata

\begin{tabular}{ll}
\hline Primer/probe & \multicolumn{1}{c}{ Sequence $\left(\mathbf{5}^{\prime}\right.$ to $\left.\mathbf{3}^{\prime}\right)$} \\
\hline A. solani & \\
129 forward primer & \\
129 reverse primer & \\
129 mutant (TTG) & AGAACTCTAGTATGAACTATTGGTACTGTTATC \\
129 mutant (TTA) & CAAACCATTTTGGCTATGTTGGT \\
129 wild type (TTC) & [VIC] CCCAGCAAAGCTG \\
129 mutant (CTC) & [FAM] AACCCAGTAAAGCTG \\
A. alternata & [VIC] AACCCAGGAAAGCTGT \\
143 forward primer & [FAM] CCCAGGAGAGCTGT \\
143 reverse primer & \\
143 mutant (GCT) & \\
143 wild type (GGT) & TTCTTGGGATACGTCTTGCCATAC \\
& TTGACCTACTCAAGGTATAGCACTCA \\
\hline
\end{tabular}

Table 3. Isolate number, year of collection, collection location, and type of cytochrome $b$ detected in Alternaria solani and A. alternata used in the quinone outside inhibitor (QoI) resistance stability test

\begin{tabular}{|c|c|c|c|c|c|c|c|}
\hline \multirow[b]{2}{*}{ Species } & \multirow[b]{2}{*}{ Isolate no. } & \multirow[b]{2}{*}{ Year } & \multirow[b]{2}{*}{ Location } & \multicolumn{2}{|l|}{ Initial } & \multicolumn{2}{|c|}{ After subculturing on azoxystrobin } \\
\hline & & & & Genotype of cytochrome $b^{y}$ & Sensitivity to $\mathbf{Q o I}^{\mathbf{z}}$ & Genotype of cytochrome $b$ & Sensitivity to QoI \\
\hline \multirow{3}{*}{ A. solani } & As1 & 2016 & Arena & TTC, CTC & Resistant & TTC, CTC & Resistant \\
\hline & As2 & 2016 & Madison & TTC, TTA, CTC & Resistant & TTC, TTA, CTC & Resistant \\
\hline & As3 & 2016 & Arena & TTC, TTA, TTG & Resistant & TTC, TTA, TTG & Resistant \\
\hline \multirow[t]{3}{*}{ A. alternata } & Aa1 & 2017 & Plover & GGT & Sensitive & GGT, GCT & Resistant \\
\hline & $\mathrm{Aa} 2$ & 2017 & Plover & GGT, GCT & Resistant & GGT, GCT & Resistant \\
\hline & Aa3 & 2017 & Plover & GGT, GCT & Resistant & GGT, GCT & Resistant \\
\hline
\end{tabular}

${ }^{y}$ For $A$. solani, mutations were in amino acid 129 in the cytochrome $b$ gene; for A. alternata, the mutation was in amino acid 143 in the cytochrome $b$ gene.

${ }^{\mathrm{z}}$ Alternaria solani with F129L and A. alternata with G143A were considered as QoI resistant. 
Determination of spatiotemporal distribution frequency of mutations conferring QoI resistance in A. alternata. Unlike A. solani, only a portion of the A. alternata isolates carried the mutations conferring QoI resistance, and that portion showed a spatiotemporal dynamic. The overall percentage of A. alternata isolates carrying the G143A mutation was 56, 45, and 51\% in 2015, 2016, and 2017, respectively (Table 5). Despite different fungicide programs and the number of QoI applications used in fields, the frequency of $A$. alternata isolates carrying G143A mutations from the commercial fields over the 3 years was similar $\left(\chi^{2}=2.4, d f=2, P=0.2971\right)$ according to the Pearson $\chi^{2}$ test (Table 5). However, the frequency of QoI resistance in A. alternata changed over the 3 years in Arena $(P<$ $0.01)$, Hancock $(P<0.01)$, and Madison $(P<0.01)$ but remained the same in Plover $(P=0.2740)$. The frequency of $A$. alternata isolates carrying G143A mutations from the Madison organic fields was significantly lower than that in Arena and moderately lower than Hancock and Plover based on results of a Tukey test (Table 5). From early to late season (Table 6), the frequency of QoI resistance in $A$. alternata increased in $2015(P=0.0109)$ and $2017(P=0.0159)$ but stayed the same in $2016(P=0.2083)$.

Growth rate and $\mathrm{EC}_{50}$ stability with QoI selection pressure. In general, mycelial growth and $\mathrm{EC}_{50}$ of the selected $A$. solani isolates

Table 4. Collection year, location, time, number of isolates, number of isolates with wild-type cytochrome $b$, and number of isolates with amino acid 129 mutations in cytochrome $b$ of Alternaria solani

\begin{tabular}{|c|c|c|c|c|c|c|c|c|c|c|}
\hline \multirow[b]{2}{*}{ Year } & \multirow[b]{2}{*}{ Location } & \multirow[b]{2}{*}{ Time } & \multirow[b]{2}{*}{ No. of isolates } & \multirow{2}{*}{$\frac{\text { Wild type }}{\text { TTC }}$} & \multicolumn{6}{|c|}{ Mutant type } \\
\hline & & & & & $\overline{\text { TTA }}$ & $(\%)$ & TTG & $(\%)$ & CTC & $(\%)$ \\
\hline \multirow[t]{8}{*}{2015} & Arena & June & 3 & 0 & 3 & 100 & 0 & 0 & 0 & 0 \\
\hline & & August & 13 & 0 & 11 & 85 & 1 & 8 & 1 & 8 \\
\hline & Hancock & June & 9 & 0 & 9 & 100 & 0 & 0 & 0 & 0 \\
\hline & & August & 8 & 0 & 8 & 100 & 0 & 0 & 0 & 0 \\
\hline & Plover & June & 15 & 0 & 14 & 93 & 1 & 7 & 0 & 0 \\
\hline & & August $^{t}$ & & & & & & & & \\
\hline & Madison & June & 0 & 0 & 0 & 0 & 0 & 0 & 0 & 0 \\
\hline & & August & 4 & 0 & 4 & 100 & 0 & 0 & 0 & 0 \\
\hline \multirow[t]{8}{*}{2016} & Arena & June $^{\mathrm{u}}$ & 20 & 0 & 19 & 95 & 2 & 10 & 1 & 5 \\
\hline & & August ${ }^{\mathrm{v}}$ & 22 & 0 & 22 & 100 & 3 & 14 & 0 & 0 \\
\hline & Hancock & June & 1 & 0 & 1 & 100 & 0 & 0 & 0 & 0 \\
\hline & & August & 16 & 0 & 16 & 100 & 0 & 0 & 0 & 0 \\
\hline & Plover & June & 9 & 0 & 9 & 100 & 0 & 0 & 0 & 0 \\
\hline & & August & 19 & 0 & 19 & 100 & 0 & 0 & 0 & 0 \\
\hline & Madison & June & 0 & 0 & 0 & 0 & 0 & 0 & 0 & 0 \\
\hline & & August ${ }^{\mathrm{w}}$ & 21 & 0 & 20 & 95 & 0 & 0 & 7 & 33 \\
\hline \multirow[t]{8}{*}{2017} & Arena & June & 0 & 0 & 0 & 0 & 0 & 0 & 0 & 0 \\
\hline & & August $^{\mathrm{x}}$ & 25 & 0 & 25 & 100 & 1 & 4 & 0 & 0 \\
\hline & Hancock & June & 0 & 0 & 0 & 0 & 0 & 0 & 0 & 0 \\
\hline & & August $\mathrm{y}$ & 18 & 0 & 18 & 100 & 1 & 6 & 0 & 0 \\
\hline & Plover & June & 0 & 0 & 0 & 0 & 0 & 0 & 0 & 0 \\
\hline & & August ${ }^{\mathrm{z}}$ & 24 & 0 & 23 & 96 & 1 & 4 & 1 & 4 \\
\hline & Madison & June & 0 & 0 & 0 & 0 & 0 & 0 & 0 & 0 \\
\hline & & August & 3 & 0 & 3 & 100 & 0 & 0 & 0 & 0 \\
\hline
\end{tabular}

${ }^{t}$ Lack of data as a result of early vine kill and harvest of the potato crop.

u Two isolates had TTA and TTG, and one isolate had CTC.

$\checkmark$ Three isolates had TTA and TTG.

${ }^{\text {w }}$ Six isolates had TTA and CTC, and one isolate had CTC.

$x$ One isolate had TTA and TTG.

y One isolate had TTA and TTG.

z One isolate had TTA and TTG, and one isolate had CTC.

Table 5. Number of Alternaria alternata isolates, number of A. alternata isolates that carried the G143A mutation conferring resistance to quinone outside inhibitors (QoI) collected from each field during 2015 to 2017, and frequency of A. alternata isolates that carried mutations

\begin{tabular}{|c|c|c|c|c|c|c|}
\hline \multirow[b]{2}{*}{ Year } & \multirow[b]{2}{*}{ No. of isolates } & \multicolumn{4}{|c|}{ Location } & \multirow[b]{2}{*}{ Total } \\
\hline & & Arena & Hancock & Plover & Madison & \\
\hline \multirow[t]{3}{*}{2015} & Total & 21 & 28 & 12 & 27 & 88 \\
\hline & Carried mutation & 19 & 23 & 5 & 2 & 49 \\
\hline & Frequency $(\%)$ & 90 & 82 & 42 & 7 & 56 \\
\hline \multirow[t]{3}{*}{2016} & Total & 31 & 21 & 40 & 39 & 131 \\
\hline & Carried mutation & 20 & 8 & 21 & 10 & 59 \\
\hline & Frequency $(\%)$ & 65 & 38 & 53 & 26 & 45 \\
\hline \multirow[t]{3}{*}{2017} & Total & 47 & 41 & 36 & 48 & 172 \\
\hline & Carried mutation & 26 & 25 & 18 & 19 & 88 \\
\hline & Frequency $(\%)$ & 55 & 61 & 50 & 40 & 51 \\
\hline Mean frequency $(\%)^{\mathrm{x}}$ & & $70.1 \pm 10.5$ & $60.4 \pm 12.7$ & $48.1 \pm 3.3$ & $24.2 \pm 9.3$ & \\
\hline Tukey test $P<0.05^{y}$ & & $\mathrm{a}$ & $a b$ & $a b$ & $\mathrm{~b}$ & \\
\hline Pearson $\chi^{2}$ test $^{\mathrm{z}}$ & & $\chi_{2}^{2}=31.0, P<0.01$ & $\chi_{2}^{2}=16.9, P<0.01$ & $\chi_{2}^{2}=2.6, P=0.2740$ & $\chi_{2}^{2}=29.8, P<0.01$ & $\chi_{2}^{2}=2.4, P=0.2971$ \\
\hline
\end{tabular}


increased with additional subculturing on CV8 amended with AZ, and these values remained the same when subcultured on CV8 (Fig. 1; Table 7). From the first transfer to the fifth transfer, mycelial growth of A. solani isolates As1 and As3 increased when grown only on AZamended media, but the $\mathrm{EC}_{50}$ remained unchanged (Fig. 1; Table 7). However, for A. solani isolate As2, both $\mathrm{EC}_{50}$ and mycelial growth values increased $(P<0.05$ for both) from the first subculture to the fifth when constantly grown on AZ-amended media (Fig. 1; Table 7).

For the selected A. alternata isolates, mycelial growth of isolate Aa1 increased from the first subculture to the fifth, but the growth

Table 6. Collection year, location, time, number of isolates, number of isolates with wild-type cytochrome $b$, and number of isolates with amino acid 143 mutations in cytochrome $b$ of Alternaria alternata

\begin{tabular}{|c|c|c|c|c|c|c|}
\hline \multirow[b]{2}{*}{ Year } & \multirow[b]{2}{*}{ Location } & \multirow[b]{2}{*}{ Time } & \multirow[b]{2}{*}{ No. of isolates } & \multirow{2}{*}{$\frac{\text { Wild type }^{\mathrm{v}}}{\text { GGT }}$} & \multicolumn{2}{|c|}{$\begin{array}{c}\text { Mutant } \\
\text { type }\end{array}$} \\
\hline & & & & & GCT & $(\%)$ \\
\hline \multirow[t]{8}{*}{$2015^{\mathrm{w}}$} & Arena & June & 4 & 1 & 3 & 75 \\
\hline & & August & 17 & 1 & 16 & 94 \\
\hline & Hancock & June & 12 & 3 & 9 & 75 \\
\hline & & August & 16 & 2 & 14 & 88 \\
\hline & Plover & June & 12 & 7 & 5 & 42 \\
\hline & & August $^{\mathrm{x}}$ & & & & \\
\hline & Madison & June & 11 & 11 & 0 & 0 \\
\hline & & August & 16 & 14 & 2 & 13 \\
\hline \multirow[t]{8}{*}{$2016^{y}$} & Arena & June & 9 & 4 & 5 & 56 \\
\hline & & August & 22 & 7 & 15 & 68 \\
\hline & Hancock & June & 10 & 5 & 5 & 50 \\
\hline & & August & 11 & 8 & 3 & 27 \\
\hline & Plover & June & 16 & 12 & 4 & 25 \\
\hline & & August & 24 & 7 & 17 & 71 \\
\hline & Madison & June & 22 & 18 & 4 & 18 \\
\hline & & August & 17 & 11 & 6 & 35 \\
\hline \multirow[t]{8}{*}{$2017^{z}$} & Arena & June & 26 & 18 & 8 & 31 \\
\hline & & August & 21 & 3 & 18 & 86 \\
\hline & Hancock & June & 23 & 15 & 8 & 35 \\
\hline & & August & 18 & 1 & 17 & 94 \\
\hline & Plover & June & 19 & 11 & 8 & 42 \\
\hline & & August & 17 & 7 & 10 & 59 \\
\hline & Madison & June & 26 & 19 & 7 & 27 \\
\hline & & August & 22 & 10 & 12 & 55 \\
\hline
\end{tabular}

$\checkmark$ Wild-type isolates do not have the G143A mutation.

${ }^{\mathrm{w}}$ Resistance \% (August) $>$ resistance \% (June), $t=6.667, d f=2, P=0.0109$.

${ }^{x}$ Lack of data as a result of early vine kill and harvest.

y Resistance \% (August) $>$ resistance \% (June), $t=0.9398, d f=3, P=0.2083$.

${ }^{\mathrm{z}}$ Resistance \% (August) $>$ resistance \% (June), $t=3.811, d f=3, P=0.0159$. of isolates $\mathrm{Aa} 2$ and $\mathrm{Aa} 3$ remained unchanged (Fig. 2). The $\mathrm{EC}_{50}$ of isolate $\mathrm{Aa} 1$ and $\mathrm{Aa} 3$ increased with additional subculturing on CV8 amended with $\mathrm{AZ}$ (Table 8). The $\mathrm{EC}_{50}$ of isolate $\mathrm{Aa} 2$ exceeded $10 \mathrm{mg} /$ liter for subcultures grown on CV8 and on AZ-amended CV8. The $\mathrm{EC}_{50}$ value of the third and fifth transfers of isolate Aa3 on AZamended media also exceeded $10 \mathrm{mg} / \mathrm{liter}$ starting from the third transfer (Table 8).

The TaqMan genotype assay revealed the same codon types of 129 in the cytochrome $b$ gene in A. solani isolates and 143 in the cytochrome $b$ gene in A. alternata isolates after serial culturing on CV8 media or AZ-amended media, with the exception of A. alternata isolate Aa1 (Table 3). The mutated codon type of GCT was detected in the third and fifth transfers of A. alternata isolate Aa1 on media amended with AZ (Table 3).

\section{Discussion}

This study documented the presence of QoI resistance in both $A$. solani as well as A. alternata from several potato production locations in Wisconsin. We found a consistently high, season-long frequency of $A$. solani isolates carrying QoI resistant mutations and a trend of increasing frequency of $A$. alternata isolates carrying QoI resistance from early season to late production season. Such resistance could be selected rapidly, within just one culture transfer on media amended with AZ, a common, representative QoI active ingredient. The resistance was stable for at least five culture transfers on nonselective media.

The cytochrome $b$ TaqMan assay used in this study detected mutations in the cytochrome $b$ gene in both Alternaria species, indicating that all of the A. solani isolates collected were genotype II or "U.S. genotype" as defined by Leiminger et al. (2014). Both genotypes I and II were discovered in Germany; however, the distribution of the two genotypes in the United States is unclear (Bauske et al. 2018). With the isolates collected in this study, it is likely that genotype II is the predominant, if not exclusive, genotype in Wisconsin.

Wild-type codon 129 in the cytochrome $b$ gene was detected in all of the $A$. solani isolates, indicating that there was a significant genetic shift attributable to QoI selection pressure. Because $A$. solani is a specific pathogen on potatoes and tomatoes, the pathogen population has been under QoI selection pressure routinely since 1999 (the year in which $\mathrm{AZ}$ was registered for use on potato). As a consequence of such constant selection pressure, the resistant isolates may have become the natural population, with mutations now fixed in most field-collected resistant isolates (Van Leeuwen et al. 2008). Even in the organically managed field in Madison, where QoI fungicides were not applied, the $A$. solani isolates showed mutations linked to QoI resistance. We do not discount the possibility that the initial inoculum of these isolates could have come from infected seed potatoes

\section{Alternaria solani isolates}
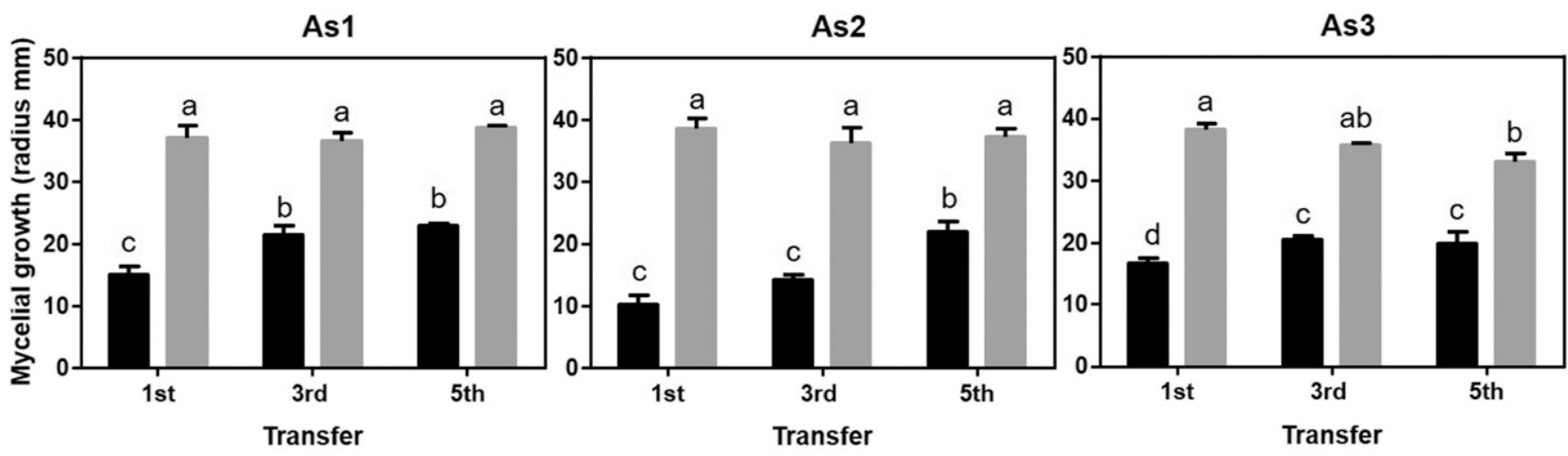

Grown on CV 8 with AZ + SHAM Grown on CV8

Fig. 1. Comparison of Alternaria solani mycelial growth at day 10 when transferred and grown on clarified V8 juice (CV8) amended with 1 mg/liter of azoxystrobin (AZ) and 100 mg/liter of salicylhydroxamic acid (SHAM) (shown as black columns) and CV8 without AZ and SHAM (shown as gray columns) one, three, and five times. Different letters above the columns indicate significant differences at $\alpha=0.05$ based on the Tukey test. 
(Secor and Gudmestad 1999) or been windblown from other conventional fields in which QoIs have been applied.

Different cytochrome $b$ mutation types were present in A. solani, although TTA was the most prevalent for codon 129. This is consistent with a previous study by Rosenzweig et al. (2008a) which investigated isolates collected in 2001 to 2003 in Wisconsin. In their study, no significant differences in sensitivity to $\mathrm{AZ}$ were observed among $\mathrm{A}$. solani isolates carrying different types of mutations. All of these mutation types led to the same amino acid shift, indicating that the influence on sensitivity to QoIs was likely the same, regardless of the mutation type. It is possible that the population of TTA mutant type was selected first when QoIs were initially used and then accumulated subsequently.

Table 7. $\mathrm{EC}_{50}$ values of Alternaria solani when subcultured on clarified V8 juice (CV8) agar media amended with and without $1 \mathrm{mg} /$ liter of azoxystrobin (AZ) and $100 \mathrm{mg} /$ liter of salicylhydroxamic acid (SHAM)

\begin{tabular}{|c|c|c|c|c|c|c|c|}
\hline \multirow[b]{2}{*}{ A. solani } & \multirow[b]{2}{*}{ Subculture transfer } & \multicolumn{3}{|c|}{ Grown on CV8 with $1 \mathrm{mg} /$ liter of $\mathrm{AZ}$} & \multicolumn{3}{|c|}{ Grown on CV8 } \\
\hline & & Mean EC $_{50}(\mathrm{mg} / \text { liter })^{\mathrm{x}}$ & Standard error ${ }^{y}$ & $P<0.05^{\mathrm{z}}$ & Mean $\mathrm{EC}_{50}$ (mg/liter) & Standard error & $P<0.05$ \\
\hline \multirow[t]{3}{*}{ Isolate As1 } & First & 3.425 & 0.778 & $\mathrm{a}$ & 3.438 & 0.207 & $\mathrm{a}$ \\
\hline & Third & 1.323 & 0.180 & $\mathrm{a}$ & 2.894 & 1.108 & $\mathrm{a}$ \\
\hline & Fifth & 1.923 & 0.024 & a & 3.543 & 1.080 & a \\
\hline \multirow[t]{3}{*}{ Isolate As2 } & First & 0.247 & 0.035 & $\mathrm{~b}$ & 0.037 & 0.017 & $\mathrm{c}$ \\
\hline & Third & 0.277 & 0.076 & $a b$ & 0.209 & 0.004 & $\mathrm{bc}$ \\
\hline & Fifth & 0.452 & 0.024 & $\mathrm{a}$ & 0.034 & 0.017 & c \\
\hline \multirow[t]{3}{*}{ Isolate As3 } & First & 2.700 & 0.842 & $\mathrm{a}$ & 3.319 & 0.342 & $\mathrm{a}$ \\
\hline & Third & 2.745 & 0.814 & $\mathrm{a}$ & 3.401 & 0.412 & a \\
\hline & Fifth & 3.979 & 1.056 & $\mathrm{a}$ & 3.273 & 0.131 & a \\
\hline
\end{tabular}

${ }^{\mathrm{x}} \mathrm{The}_{\mathrm{EC}} \mathrm{E}_{50}$ of each isolate was based on conidial germination rates on water agar amended with $0,0.001,0.01,0.1,1$, and $10 \mathrm{ml} / \mathrm{liter}$ of $\mathrm{AZ}$ and $100 \mathrm{mg} / \mathrm{liter}$ of SHAM.

${ }^{y}$ Standard error based on three replications.

${ }^{\mathrm{z}}$ Comparisons were made among the three subculture transfers on $\mathrm{AZ}$ and CV8 of each isolate. The same letter indicates no significant difference at the $\alpha=0.05$ significance level based on the Tukey test.

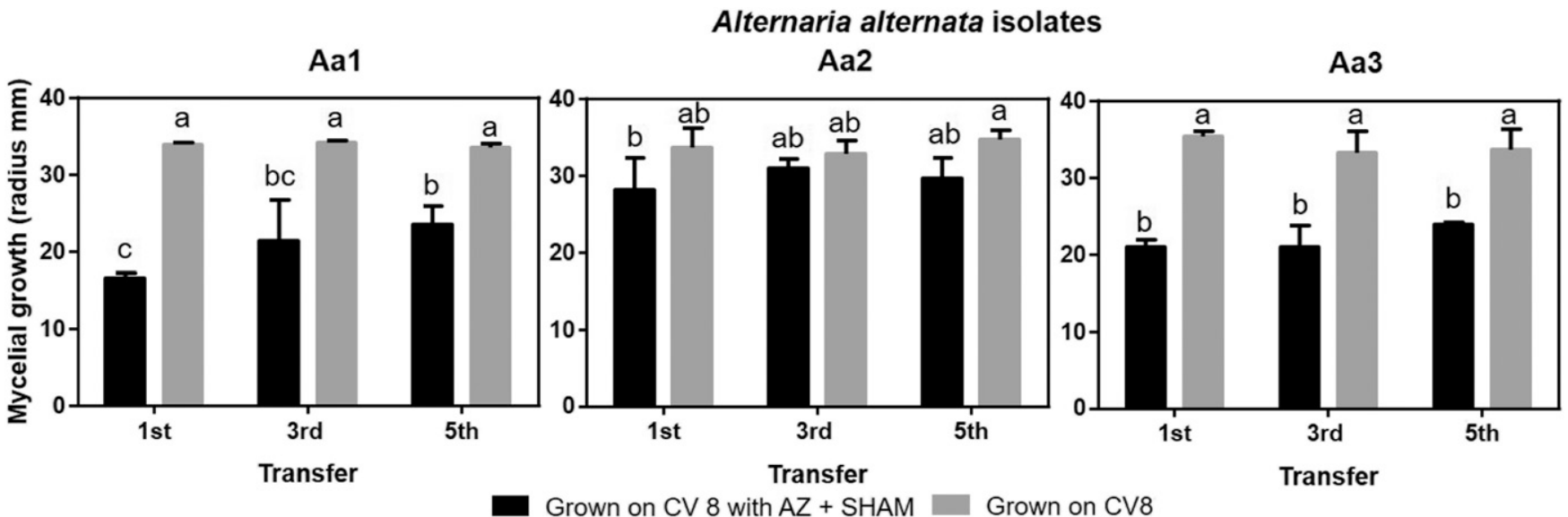

Fig. 2. Comparison of Alternaria alternata mycelial growth at day 7 when transferred and grown on clarified V8 juice (CV8) amended with 1 mg/liter azoxystrobin (AZ) and 100 $\mathrm{mg} /$ liter of salicylhydroxamic acid (SHAM) (shown as black columns) and CV8 without AZ and SHAM (shown as gray columns) one, three, and five times. Different letters above the columns indicate significant differences at $\alpha=0.05$ based on the Tukey test.

Table 8. $\mathrm{EC}_{50}$ values of Alternaria alternata when subcultured on clarified V8 juice (CV8) agar media amended with and without $1 \mathrm{mg} /$ liter of azoxystrobin (AZ) and $100 \mathrm{mg} /$ liter of salicylhydroxamic acid (SHAM)

\begin{tabular}{|c|c|c|c|c|c|c|c|}
\hline \multirow[b]{2}{*}{ A. alternata } & \multirow[b]{2}{*}{ Subculture transfer } & \multicolumn{3}{|c|}{ Grown on CV8 with $1 \mathrm{mg} /$ liter AZ } & \multicolumn{3}{|c|}{ Grown on CV8 } \\
\hline & & $\overline{\text { Mean EC }}$ Ev $_{5}(\mathrm{mg} / \text { liter })^{\mathrm{w}}$ & Standard error ${ }^{x}$ & $P<0.05^{y}$ & Mean EC E0 $_{50}(\mathrm{mg} /$ liter) & Standard error & $P<0.05$ \\
\hline \multirow[t]{3}{*}{ Isolate $\mathrm{Aa} 1$} & First & 1.375 & 0.050 & $\mathrm{bc}$ & 0.479 & 0.015 & $\mathrm{c}$ \\
\hline & Third & 3.206 & 1.421 & $\mathrm{~b}$ & 0.487 & 0.082 & $\mathrm{c}$ \\
\hline & Fifth & 8.521 & 0.804 & $\mathrm{a}$ & 0.662 & 0.049 & c \\
\hline \multirow[t]{3}{*}{ Isolate $\mathrm{Aa} 2$} & First & $>10^{\mathrm{z}}$ & & & $>10$ & & \\
\hline & Third & $>10$ & & & $>10$ & & \\
\hline & Fifth & $>10$ & & & $>10$ & & \\
\hline \multirow[t]{3}{*}{ Isolate Aa3 } & First & 2.033 & 0.137 & a & 0.760 & 0.246 & $\mathrm{~b}$ \\
\hline & Third & $>10$ & & & 0.535 & 0.110 & $\mathrm{~b}$ \\
\hline & Fifth & $>10$ & & & 0.796 & 0.031 & $\mathrm{~b}$ \\
\hline
\end{tabular}

${ }^{\mathrm{w}} \mathrm{The} \mathrm{EC}_{50}$ of each isolate was based on conidial germination rates on water agar amended with $0,0.001,0.01,0.1,1$, and $10 \mathrm{ml} / \mathrm{liter}$ of $\mathrm{AZ}$ and $100 \mathrm{mg} / \mathrm{liter}$ of SHAM.

$x$ Standard error based on three replications.

${ }^{y}$ Comparisons were made among the three subculture transfers on AZ and CV8 of each isolate. The same letter indicates no significant difference at the $\alpha=0.05$ significance level based on the Tukey test.

${ }^{\mathrm{z}} \mathrm{EC}_{50}$ exceeded $10 \mathrm{mg} /$ /iter, so no statistical analysis could be conducted. 
Overall, the frequency of A. alternata carrying G143A did not change throughout the 3 years of sampling, but the frequency varied between locations. A QoI application was considered the driving force of the higher frequency of QoI resistance in A. alternata isolates from the commercial potato fields (Samuel et al. 2011; Toffolatti et al. 2007). With QoI fungicide application, the overall frequency of A. alternata carrying G143A was significantly or moderately higher in the commercial fields where QoIs were applied than the organic field where QoIs were not applied over the years of this study. Without selection pressure, most of the A. alternata isolates carrying the G143A mutation might have originated from outside sources. For example, they may potentially be QoI resistant isolates windblown from another potato field or fields of other host crops where QoIs had been applied (McCartney et al. 1993; Rotem 1994).

The frequency of $A$. alternata isolates carrying the G143A mutation changed every year. The potential rate at which QoI resistance could develop in both Alternaria spp. is high. However, unlike the consistently high frequency of $A$. solani isolates carrying F129L, the frequency of A. alternata isolates carrying G143A mutation started low in the early season and increased in the later season. Because there was no fitness cost to carrying G143A (Fan et al. 2015; Karaoglanidis et al. 2011; Vega and Dewdney 2014), the sensitivity of $A$. alternata to QoI is unlikely to return. It is important to note that this trend is based on only two time points within the growing season and more sampling would be needed in order to better assess mutation frequencies. The increasing frequency of $A$. alternata isolates carrying G143A did not seem to be significantly correlated to the number of QoI applications made each year in the fields used in this study. This could be a result of the wide host range and conidial movement of A. alternata that may have complicated the process of selection of resistant isolates by QoI application (Tymon and Johnson 2014). Given that $A$. alternata has a broad host range, including Cucurbitaceae species, citrus, and Syringa species, to name a few (Mmbaga et al. 2011; Vakalounakis 1990; Vega et al. 2012), it is possible that there are wild-type populations maintained in alternative host species and that the conidia moved to the potato fields on prevailing wind currents after primary infection. Therefore, the frequency of A. alternata isolates carrying the mutation increased from early season to late season every year, but it never reached as high as that of $A$. solani isolates although they received the same fungicide application.

The high potential rate at which QoI resistance could develop for both Alternaria species was evidenced in the serial transfers of both species on $\mathrm{AZ}$-amended media. When $\mathrm{EC}_{50}$ was lower than the selection pressure, resistance could be selected for and accumulate quickly, as a significantly elevated $\mathrm{EC}_{50}$ after one transfer on AZamended media was observed. Such phenomena were observed with A. solani isolate As2 and A. alternata isolates Aa1 and Aa3. The rapid selection was driven mainly by the abundant production of asexual conidia, as suggested by Fraaije et al. (2005). Resistance to $\mathrm{AZ}$ was shown by increasing mycelia growth from the first to the fifth transfers, but variations may occur and the $\mathrm{EC}_{50}$ values of the subcultures in one transfer of one isolate may not be identical to another. The target of QoIs is cytochrome $b$, a mitochondrial gene. Mitochondria in cells divide unevenly and therefore the isolates transmit their resistant and sensitive types of cytochrome $b$ genes to progeny in variable ratios (Van Leeuwen et al. 2008). The relative abundance of the wild-type allele of cytochrome $b$ was found to influence the sensitivity level of the isolates to QoIs (Lesemann et al. 2006; Villani and Cox 2014), which may explain the difference in $\mathrm{EC}_{50}$ when two isolates had the same codon types such as A. alternata isolates Aa2 and Aa3.

QoI resistance in both Alternaria species was stable for at least five generations, even when the selection pressure of QoI was removed. In the field, although QoI fungicides were not applied, (e.g., in 2015 in the Hancock field and 2016 in the Plover field), the frequency of $A$. solani isolates carrying the QoI resistance mutation was $100 \%$ and the frequency of $A$. alternata isolates carrying the QoI resistance mutation also showed an increasing trend from early season to late season. Such stability in QoI resistance was evidenced in the serial transfers of QoI resistant isolates on AZ-amended media as well. When QoIs were not present, or the QoI concentration was lower than the $\mathrm{EC}_{50}$ of the isolates, neither $\mathrm{EC}_{50}$ values of these isolates nor the codon types of the 129 codon in their cytochrome $b$ changed over five serial transfers. For example, the $\mathrm{EC}_{50}$ of $A$. solani isolates As1 and As3 did not change over five serial transfers, and the $\mathrm{EC}_{50}$ of all the isolates grown on CV8 did not change either. Similar phenomena were observed in other studies (Karaoglanidis et al. 2011; Pasche and Gudmestad 2008; Vega and Dewdney 2014), indicating that carrying the mutation conferring QoI resistance does not have a fitness cost for the pathogens. Therefore, mutations in cytochrome $b$ conferring QoI resistance are stable in pathogen populations to some degree (Ishii et al. 2007; Lesemann et al. 2006; Samuel et al. 2011).

In summary, the results of this study showed that the frequency of A. solani isolates carrying QoI resistance mutations was consistently high in Wisconsin. The resistance in A. alternata isolates, however, showed a temporal pattern in which the resistance frequency started out low in early season and increased in late season. Because mutations that confer QoI resistance are associated with the mitochondrial cytochrome $b$ gene, the relative abundance of mutations in the gene of one Alternaria isolate may be related to the level of its QoI resistance. The resistance to QoIs was stable in the Alternaria species for at least a few generations. Therefore, stopping QoI application for a few years may not help re-establish the sensitivity of the pathogens. QoIs may still be effective for controlling brown spot, but likely only early in the growing season (approximately June). Fungicides with alternative modes of action may be applied to achieve a more effective early blight and brown spot disease management.

\section{Acknowledgments}

We thank our grower collaborators for allowing us access to their fields for sampling and Dr. Monica Yu Chen for critically reviewing this manuscript.

\section{Literature Cited}

Agrios, G. N. 2005. Plant Pathology, 5th ed. Elsevier Academic Press, Amsterdam, Netherlands.

Bartlett, D. W., Clough, J. M., Godwin, J. R., Hall, A. A., Hamer, M., and ParrDobrzanski, B. 2002. The strobilurin fungicides. Pest Manag. Sci. 58:649-662.

Bauske, M. J., Mallik, I., Yellareddygari, S. K. R., and Gudmestad, N. C. 2018. Spatial and temporal distribution of mutations conferring QoI and SDHI resistance in Alternaria solani across the United States. Plant Dis. 102 349-358.

Bok, J. W., and Keller, N. P. 2012. Fast and easy method for construction of plasmid vectors using modified quick-change mutagenesis. Methods Mol. Biol. 944:163-174.

Fairchild, K. L., Miles, T. D., and Wharton, P. S. 2013. Assessing fungicide resistance in populations of Alternaria in Idaho potato fields. Crop Prot. 49: 31-39.

Fan, Z., Yang, J. H., Fan, F., Luo, C. X., and Schnabel, G. 2015. Fitness and competitive ability of Alternaria alternata field isolates with resistance to SDHI, QoI, and MBC fungicides. Plant Dis. 99:1744-1750.

Fraaije, B. A., Cools, H. J., Fountaine, J., Lovell, D. J., Motteram, J., West, J. S., and Lucas, J. A. 2005. Role of ascospores in further spread of QoI-resistan cytochrome $b$ alleles (G143A) in field populations of Mycosphaerella graminicola. Phytopathology 95:933-941.

Grasso, V., Palermo, S., Sierotzki, H., Garibaldi, A., and Gisi, U. 2006. Cytochrome $b$ gene structure and consequences tor resistance to Qo inhibitor fungicides in plant pathogens. Pest Manag. Sci. 62:465-472.

Hong, S. G., Cramer, R. A., Lawrence, C. B., and Pryor, B. M. 2005. Alt a 1 allergen homologs from Alternaria and related taxa: analysis of phylogenetic content and secondary structure. Fungal Genet. Biol. 42:119-129.

Ishii, H., Yano, K., Date, H., Furuta, A., Sagehashi, Y., Yamaguchi, T., Sugiyama, T., Nishimura, K., and Hasama, W. 2007. Molecular characterization and diagnosis of QoI resistance in cucumber and eggplant fungal pathogens. Phytopathology 97:1458-1466.

Karaoglanidis, G. S., Luo, Y., and Michailides, T. J. 2011. Competitive ability and fitness of Alternaria alternata isolates resistant to QoI fungicides. Plant Dis. 95: 178-182.

Leiminger, J. H., Adolf, B., and Hausladen, H. 2014. Occurrence of the F129L mutation in Alternaria solani populations in Germany in response to QoI application, and its effect on sensitivity. Plant Pathol. 63:640-650.

Lesemann, S. S., Schimpke, S., Dunemann, F., and Deising, H. B. 2006. Mitochondrial heteroplasmy for the cytochrome $\mathrm{b}$ gene controls the level of strobilurin resistance in the apple powdery mildew fungus Podosphaera leucotricha (Ell. \& Ev.) ES Salmon. J. Plant Dis. Prot. 113:259-266. 
Ma, Z. H., and Michailides, T. J. 2004. A real-time PCR assay for the detection of azoxystrobin-resistant Alternaria populations from pistachio orchards in California. Crop Prot. 23:1259-1263.

McCartney, H. A., Schmechel, D., and Lacey, M. E. 1993. Aerodynamic diameter of conidia of Alternaria species. Plant Pathol. 42:280-286.

Mmbaga, M. T., Shi, A. N., and Kim, M. S. 2011. Identification of Alternaria alternata as a causal agent for leaf blight in Syringa species. Plant Pathol. J. 27:120-127.

Pasche, J. S., and Gudmestad, N. C. 2008. Prevalence, competitive fitness and impact of the F129L mutation in Alternaria solani from the United States. Crop Prot. 27:427-435.

Pasche, J. S., Piche, L. M., and Gudmestad, N. C. 2005. Effect of the F129L mutation in Alternaria solani on fungicides affecting mitochondrial respiration. Plant Dis. 89:269-278.

Pasche, J. S., Wharam, C. M., and Gudmestad, N. C. 2004. Shift in sensitivity of Alternaria solani in response to Q(o)I fungicides. Plant Dis. 88:181-187.

Pscheidt, J. W., and Stevenson, W. R. 1986. Comparison of forecasting methods for control of potato early blight in Wisconsin. Plant Dis. 70:915-920.

Rosenzweig, N., Atallah, Z. K., Olaya, G., and Stevenson, W. R. 2008a. Evaluation of QoI fungicide application strategies for managing fungicide resistance and potato early blight epidemics in Wisconsin. Plant Dis. 92: 561-568.

Rosenzweig, N., Olaya, G., Atallah, Z. K., Cleere, S., Stanger, C., and Stevenson, W. R. 2008b. Monitoring and tracking changes in sensitivity to azoxystrobin fungicide in Alternaria solani in Wisconsin. Plant Dis. 92:555-560.

Rotem, J. 1994. The Genus Alternaria: Biology, Epidemiology, and Pathogenicity. American Phytopathological Society, St. Paul, MN.

Samuel, S., Papayiannis, L. C., Leroch, M., Veloukas, T., Hahn, M., and Karaoglanidis, G. S. 2011. Evaluation of the incidence of the G143A mutation and cytb intron presence in the cytochrome bc-1 gene conferring QoI resistance in Botrytis cinerea populations from several hosts. Pest Manag. Sci. 67:1029-1036.
Secor, G. A., and Gudmestad, N. C. 1999. Managing fungal diseases of potato. Can. J. Plant Pathol. 21:213-221.

Shtienberg, D., Bergeron, S. N., Nicholson, A. G., Fry, W. E., and Ewing, E. E. 1990. Development and evaluation of a general model for yield loss assessment in potatoes. Phytopathology 80:466-472.

Toffolatti, S. L., Serrati, L., Sierotzki, H., Gisi, U., and Vercesi, A. 2007. Assessment of QoI resistance in Plasmopara viticola oospores. Pest Manag. Sci. 63:194-201.

Tymon, L., and Johnson, D. A. 2014. Fungicide resistance of two species of Alternaria from potato in the Columbia Basin of Washington. Plant Dis. 98: 1648-1653.

Vakalounakis, D. J. 1990. Host range of Alternaria alternata f. sp. cucurbitae causing leaf spot of cucumber. Plant Dis. 74:227-230.

van der Waals, J. E., Korsten, L., Aveling, T. A. S., and Denner, F. D. N. 2003 Influence of environmental factors on field concentrations of Alternaria solani conidia above a South African potato crop. Phytoparasitica 31:353-364.

Van Leeuwen, T., Vanholme, B., Van Pottelberge, S., Van Nieuwenhuyse, P., Nauen, R., Tirry, L., and Denholm, I. 2008. Mitochondrial heteroplasmy and the evolution of insecticide resistance: Non-Mendelian inheritance in action. Proc. Natl. Acad. Sci. USA 105:5980-5985.

Vega, B., and Dewdney, M. M. 2014. QoI-resistance stability in relation to pathogenic and saprophytic fitness components of Alternaria alternata from citrus. Plant Dis. 98:1371-1378.

Vega, B., Liberti, D., Harmon, P. F., and Dewdney, M. M. 2012. A rapid resazurinbased microtiter assay to evaluate Qol sensitivity for Alternaria alternata isolates and their molecular characterization. Plant Dis. 96:1262-1270.

Villani, S. M., and Cox, K. D. 2014. Heteroplasmy of the cytochrome $b$ gene in Venturia inaequalis and its involvement in quantitative and practical resistance to trifloxystrobin. Phytopathology 104:945-953.

Ziogas, B. N., Baldwin, B. C., and Young, J. E. 1997. Alternative respiration: A biochemical mechanism of resistance to azoxystrobin (ICIA 5504) in Septoria tritici. Pestic. Sci. 50:28-34. 